\title{
Training of Contemporary University students and the Education of Innovative Talents
}

\author{
Zhao Wei ${ }^{1, \text { a }}$, Liu Yan ${ }^{2, b}$ \\ ${ }^{1}$ The Northest Forestry University,Harbin,150040, China \\ ${ }^{2}$ Harbin Light Industry School, Harbin,150040, China \\ aemail: zhaowei640106@163.com, bemail: ly81220@126.com
}

Keywords: The modernization of education; innovative talents;College students training

\begin{abstract}
In this paper, the contemporary college students are faced with the problem of how modern educational ideas, teaching, and the cultivation of innovative talents have problem to do a simple analysis, and put forward the concept of modern education into the training plan revision, solve student heart qualities by modern education thought. It emphasizes the use of modern educational concept innovation of curriculum system, teaching mode innovation theory, theory of teaching mode innovation, ability of students' Engineering Quality Cultivation of innovative and unique culture innovation.
\end{abstract}

\section{Introduction}

With the popularization of higher education, college students, college condition and students numbers has changed a lot. However the cultivation mode failed to adapt to these changes, and there are still exist problems in teaching and learning, theory and practice, schools and enterprises. Besides the quality education is very formalization. These problems resulting in a dilemma coexistence phenomenon which is the graduates have employment difficult and the enterprise have recruitment difficult. On one hand, college graduates are facing the enormous pressure on employment; on the other hand, the enterprises are lack of talent. Similarly, on one hand, universities have numerous research results; on the other hand, the industrial innovation is lack of competitiveness. The main reason is that the education process in China has disadvantageous, mainly manifests is that the education target is fuzzy, teachers are lack of modern education thought ,idea and engineering experience, so the students' practical ability is not strong.

Innovation student is the creative talents with innovative spirit, also has the innovative consciousness, creative thinking and creative ability. Knowledge Innovation is the core of innovation, which including not only science innovation, technology innovation and the creative application of knowledge innovation, but also relates to the system, management and culture innovation and other elements.

The traditional mode of teaching is teacher-centered teaching structure. The utility model has the advantages of fully playing the leading role of the teacher, help teachers to organize classroom teaching, management and control. But it has a big flaw, which is it ignored the initiative creativity of the students, which can't take the main role of the students. Which lead it is impossible to cultivate creative talents. Therefore, in teaching, we should make full use of modern educational technology, and adopt a variety of methods and measures, in order to train the creative thinking ability of the college students, and laid a solid foundation for the development of the innovative talents.

\section{Key Problems}

1、 The cultivation of student's psychological quality

Psychological quality is the most prone part to cause crisis among all the quality of people. If people's psychological quality once has latent crisis, it will affect the development of the individual, even cause unexpected consequences. 
Because of the one child-plan, now one-child families produced spoiled children whose independent ability is poor, and whose ability to bear in mind is poor. Many students are in an education environment basically compulsory, passive learning, poor initiative from primary school to middle school.

Although college students have relatively mature abstract logical thinking ability, have the strong powers of observation, memory and attention. But in the objective aspect, they could not get out of middle school learning and living model, many are not used to the new university life, they burden a lot of pressure; In the subjective aspect, many college students' psychological ability is not strong, for example: just indulge in self-delusion of being an university student, or disappointment with University's feeling, relax emotional and psychological, learning method is not adapt to the rest, have frustrated emotion after exams. All these problems need to be solved.

2、 Professional training program updates

In the past, the specialized training scheme only require students to have professional basic knowledge and basic skills; which made them can be engaged in relevant professional research, design, manufacture, application and integration. Its engineering education target is fuzzy, lack of communication and interaction with industry and the society. It is inevitable that engineering education like this is difficult to meet the demand of the industry.

3、 Innovation in compiling textbooks

Students need textbook which is compelling, easily understood, clear concept. We should obey these principles and try to make the content substantial. This enables the students to master reading method of 'study from thick to thin'. Textbook should meet the teaching needs of innovative education mode of talents training.

4、 The construction of teachers' team

Teachers' knowledge level and engineering and practical ability, affect students' learning status, learning level, hands-on practice ability and innovation ability. Education is successful or not depends largely on teachers. High-quality teachers is not only the core competitiveness of the colleges and universities, is also the key to cultivating innovative talents.

5、 Teaching method and teaching means

Teaching methods and teaching means should be conducive to the cultivation of the college students' self-study ability. Students want to get more knowledge must rely on self-study to enrich him. 'High score, low ability' fully reflects defects of many college students in practical ability. To overcome the disadvantageous in existing training model, we should pay attention to training students to analyze and solve problems in terms of unknown events of the innovation ability.

\section{Research Method}

1、 Strengthen the education of students' psychological quality;

We should give full play to the role of school psychological consultation; do psychological investigation with close coordination with the school counseling teachers; do early detection and prevention of psychological problems; put quality education into the teaching of modern psychology.

In the college entrance guidance, first of all, teachers should emphasize that the university study and life with the previous school learning life is different. It is subjective, initiative learning, no one forced learning. Students should learn knowledge with their own interests. So that students will drop lazy and passive learning, and become positive and active learning.

To enable students to clear the professional training objectives, training requirements, curriculum knowledge system, and employment and learning directions. Let them to understand the present situation and development trend of the professional front. We need to cultivate them to have humanity and social science literacy, to own strong social responsibility and good engineering occupation moral, and get basic ability of comprehensive use of the scientific theory and technical means to analyze and solve engineering problems.

2、The revision of the training plan should rely on discipline advantages, considering the industry, according to the enterprise and the characteristics of professional, and do social investigation

Innovative talents should abide the occupation moral culture and have strong sense of social 
responsibility, who should learn basic knowledge and basic skills, master the modern technology, own flexible use modern idea and have the ability to quickly master new knowledge, has the subjective initiative of independent thinking and problem solving, have certain management ability and strong humanistic quality, have team spirit, have international vision and international competition consciousness, have heavy engineering quality and perfect personality.

In order to put the modern education idea into teaching, Electronic Information Engineering specialty as an example, the professional training program should do the following trimming:

3、 Textbook use and construction is the basis of teaching reform, which is prerequisite to guarantee teaching quality.

By making a number of measures to encourage teachers engaged in excellent teaching material compilation and select excellent teaching material at home and abroad as a teaching book and bibliography. Textbook will have advanced knowledge of modern technology, absorbing, easily understood, clear concept and with abundant knowledge, which enables the students to master the 'from thick to thin' learning method.

4、Curriculum system innovations - build seminar system, general education and specialized course system.

Based on the principles of four-year to design the teaching plan, take the ' $3+1$ ' mode, namely the campus learning 3 years and 1 year of enterprise engineering practice training. We also compressed the theory courses and increased the practice hours. For general course and specialized course, we reduce its redundancy from course system to teaching content, avoid low level repetition. We emphasize the Engineering practice and innovation ability, build a batch of course with engineering characteristics. We will employ oriented enterprise senior engineer to guide some practical courses or programs or send our students to the enterprise to do hands-on practice. We also establish innovative class to develop and strengthen their aptitude. Outside the classroom, we establish special activities fund, carry out students' scientific research training plan, encourage students to declare research projects independently, and encourage students to engage in the science and experimental research as early as they can.

5、 Theory teaching mode innovation, reform teaching method and examination method

We adjust the teaching content mainly geared to the needs of engineering practice, explore the teaching diversity, such as combined discussion teaching and lecture class together, combined actual production and on-site interpretation together and take the problems in the production as an example. We will organize students to carry out analysis, invite enterprise engineering technology or management personnel for students, induct students into a professional teacher and mentor research topic or project development, involve in a comprehensive training for research and development ability.

When teachers in the interpretation of the teaching content, try to use blackboard (justice), body, and vivid language interpretation (need to add a small amount of multimedia dynamic demonstration). Teachers should hit the nail on the head, talk straightly to the theme (fewer words and better, not to long), which can obtain the good teaching effect. Long text projection teaching, can make students tired and lose interest. Teachers should guide the students do consciously thinking, guides the student to analyze and to speculate about possible conclusion, stir up the students' desire to explore and cultivate students' innovative thinking and innovative ability.

In curriculum design practice classes, try to be less word and more practice, strengthen the training of the students practice. We may move the class to the lab and do practice teaching. With project as the center, let the students read materials with questions and demonstrate the project. This can make the students understand and grasp the specific application process and methods and it is a good way to achieve interaction between teachers and students.

6、 Engineering quality innovation - Implementing university-enterprise cooperation

We composed a 'colleges and business joint cultivate excellence engineer steering committee 'which own the modern education idea. According to the training target, the outline of engineering practice, practice content and evaluation method will be plan jointly. The enterprise will give suggestion about the formulation of professional talent training scheme, course system, and 
practice teaching effective guidance and so on, which make the enterprise to participate in the whole process of cultivating creative personnel.

We signed the agreement on joint training with enterprises, expand the practical teaching base and through a variety of forms, and make reasonable arrangement of all kinds of practice teaching reform. We practice the double tutorial system; emphasize the advantage of outstanding enterprise mentors on the students' practical ability training. We let students to carry out the project design by a variety of ways, and students are required to complete engineering design in the enterprise practice.

Students can work in different jobs in an enterprise in turns or in different enterprise. After their engineering practice, the students have to complete a practical report. Graduation design can adopt diversified way, students can do researches according to their engineering practical problems found in the enterprise practice, and they can also choose to do scientific research under the guidance of the teachers. But the topic must have certain challenging and practical significance, and it must be a project design or research and development. They couldn't do theory research and the theory simulation thesis. The purpose of this is to cultivate and enhance students engineering design ability.

\section{Conclusion}

All in all, the overall plan of innovative entrepreneurial talent training mode reform is on the basis of innovative entrepreneurial talent training standards, to cultivate students' innovative entrepreneurial ability as the goal, to build modern innovative entrepreneurship education training system and pattern. It core is have a clear training standard of modern knowledge and ability. Research-based learning and professional quality education as the means, we should strengthen the pluralistic education fusion and do personalized and diversified training unifies, build progressive unity 'learning' education platform, give full play to the role of university-enterprise cooperation, train students the modern theory of knowledge, practice ability, innovation thinking and entrepreneurial initiative comprehensively, realize from science to engineering, from engineering to innovation and entrepreneurship. Comprehensively cultivate the students' innovative spirit, team spirit and dedication spirit, so as to cultivate high level and high quality electronic information modernization innovative entrepreneurial talent.

\section{Acknowledgement}

In this paper, the research was sponsored by the Institute of Higher Education in Heilongjiang an Province Higher education scientific research "twelfth five-year" plan project(Project No. HGJXHB $\left._{1} 110389\right)$.

\section{References}

[1] Huang Weijun. Single chip microcomputer principle and application course teaching reform research [J]. Journal of electrical teaching. Nanjing: southeast university press, 2010, 6

[2] Lv Lin. To cultivate innovative talents of the teaching method reform discussion [J]. Journal of mianyang normal university. In mianyang, mianyang normal university press, 2007, 10.

[3] Guo Guangsheng. Call for a revolution in teaching methods training innovative talents [J]. Journal of higher education in China. Beijing: higher education press in China, 18, 2011.

[4] Wang Wanshan. Innovative entrepreneurial talent training and the teaching method reform research [M]. Nanchang: jiangxi people's publishing house, in December 2008

[5] Xue Zhentian talent cultivation model of innovation. China metallurgical education [J]. Beijing: China metallurgical education press, 2011, 5. 